\title{
O Melhor Espetáculo da Terra: Crise e Regulação no Carnaval de Rua do Rio de Janeiro
}

\author{
The Best Spectacle on Earth: Crisis and Regulation in Rio de \\ Janeiro's Street Carnival
}

\author{
Ana Paula Rocha de Oliveira \\ Programa de Pós-Graduação em Sociologia e Antropologia, Universidade Federal do Rio de \\ Janeiro, Rio de Janeiro, RJ, Brasil
}

\section{Julia Galli O'Donnell}

Programa de Pós-Graduação em Sociologia e Antropologia, Universidade Federal do Rio de Janeiro, Rio de Janeiro, RJ, Brasil

\section{RESUMO}

O artigo discute de que forma o carnaval de rua pode ser pensado como resultado de disputas e negociações entre diferentes agentes do Estado e, ao mesmo tempo, como produtor de práticas e territorialidades urbanas. Para isso, parte-se da identificação de uma crise no âmbito da economia e da segurança pública, com o intuito de desenvolver uma discussão sobre o processo de regulação do carnaval de rua no Rio de Janeiro. Baseado em trabalho etnográfico realizado junto ao Ministério Público do Rio de Janeiro, o artigo tem como foco analítico os desdobramentos da construção da narrativa de crise, pensados em relação com os quadros de valores morais acionados no processo de ocupação dos espaços da cidade e no fornecimento de serviços públicos. Nesse sentido, são analisadas formas de classificação utilizadas por diferentes atores no processo de organização da festa, numa reflexão que coloca o uso do espaço urbano no centro da discussão sobre a ordem e a segurança pública.

Palavras-chave: Carnaval de Rua, Rio de Janeiro, Bloco de Carnaval, Regulação, Crise. 


\section{ABSTRACT}

The article aims to discuss how the street carnival can be thought of as a result of disputes and negotiations between different state agents and as a producer of urban practices and territorialities. It starts from the analysis of a specific event - the identification of a crisis in the economy and public safety - to develop a discussion about the process of regulation of the street carnival in Rio de Janeiro. Based on ethnographic work carried out with the Public Prosecutor's Office of Rio de Janeiro, the article focus on the unfoldings of the construction of the crisis narrative in relation to the moral frameworks triggered in the uses of streets and in the provision of public services. In this sense, we analyze the forms of classification used by different actors in the process of organizing the party, situating the uses of urban space at the center of the discussion about public order and safety.

Keywords: Street Carnival, Rio de Janeiro, Carnival Bloco, Regulation, Crisis.

\section{INTRODUÇÃ̃o}

O carnaval de rua do Rio de Janeiro é uma das maiores festividades populares do Brasil. Anualmente, milhões de foliões se aglomeram pelas ruas da cidade, dando corpo a uma festa que vem crescendo a cada ano. Estima-se que em 2018 mais de 7 milhões de pessoas participaram do carnaval de rua na capital fluminense, dentre as quais cerca de 1,6 milhões de turistas. No mesmo ano, 608 blocos desfilaram pela cidade, somando um "custo total estimado em 72,4 milhões de reais" (CORRÊA, 2019).

Apesar do sucesso revelado por números como esses, nem tudo foi festa no carnaval daquele ano. Cenas de assaltos, arrastões, saques e problemas no esquema de segurança foram intensamente midiatizados durante os dias da festa, levando o então presidente Michel Temer a afirmar que o cenário revelava uma "agressividade muito grande e uma desorganização social e até moral muito acentuada" (BANDNEWS TV, 2018). Esse contexto pôs a folia no centro de uma série de discussões e controvérsias, agravadas pelo fato de que o então governador do estado, Luiz Fernando Pezão, não apresentara um plano de segurança para os dias de carnaval (FOLHA DE SÃO PAULO, 2018). Também chamou a atenção da imprensa e de partidos de oposição a viagem do então prefeito e bispo evangélico, Marcelo Crivella, para o exterior nos dias da maior festividade da cidade (NUNES, 2018), em atitude oposta àquela tradicionalmente adotada por gestores do município. A opinião pública frente ao cenário de violência e a aparente ausência de medidas por parte dos governantes deram forma a uma sensação difusa de abandono e desordem, tanto no âmbito estadual quanto na esfera da municipalidade, o que veio a 
reforçar as narrativas de uma crise na segurança pública local.

Como ponto de partida, e acompanhando Janet Roitman (2014), é importante refletir sobre os modos pelos quais a crise se constitui como objeto de conhecimento. Reiteradamente acionada e disputada, a fim de delimitar um momento da verdade (p. 4), a crise é utilizada em construções narrativas como modo de pensar a própria história e como produtora, ela mesma, de contextos. Na conjuntura aqui analisada, a crise se refere à situação fiscal do Estado do Rio de Janeiro, seguida da intervenção federal na segurança pública do estado. Nosso objetivo é, assim, analisar como o carnaval de rua serviu (e tem servido) como espaço de disputas em torno do repertório que dá corpo às narrativas da crise (p. 11), a partir de categorias centrais à gestão do espaço urbano - tais como desordem e violência. Nesse sentido, visamos discutir o que uma "crise fiscal" e de segurança mobiliza tanto nos festejos de rua quanto nos aspectos centrais das negociações que culminam, anualmente, no desfile de centenas de blocos pela cidade durante os dias de carnaval.

Veremos como o mote da crise, muitas vezes amplificado pela imprensa cujas posições são aderidas pelo senso comum (DEWEY, 1938), é capaz de moldar tentativas específicas de regulação pela norma, mesmo que essa exceção se dê, paradoxalmente, de forma prolongada no tempo e na história. É importante destacar que o nosso foco não é indagar sobre os motivos que levaram às referidas crises, mas sim pensá-las como produtoras de sentido (ROITMAN, 2014), esboçando modos de governo que a elas se articulam, e refletir sobre como tais governos acabam modulando as negociações em torno do carnaval de rua.

Parte integrante da narrativa sobre a crise, os números que inauguram este artigo e o repertório da escassez de recursos públicos a ela relacionados (FREIRE, 2019) são também elementos centrais a serem avaliados. No âmbito da festa, essas condições se expressam, por exemplo, na reiteração da insuficiência operacional de polícias e da capacidade de atendimento dos órgãos de saúde pública, além da falta de verba pública de modo geral. A noção de escassez de recursos está no cerne de uma série de intervenções estatais (FREIRE, 2019) e serve como mobilizadora de processos de apropriação da festa pelo mercado privado, de responsabilizações da sociedade civil organizadora de blocos de rua e de procedimentos burocráticos para a realização da festa, impondo novas prerrogativas à ocupação da rua nos dias de carnaval.

Assim, partimos daquilo que na pesquisa de campo se mostrou significativo aos interlocutores no espaço de disputas dentro do qual se organiza não apenas a festa, mas também a política, os documentos e as diferentes vertentes do Estado que atuam na preparação do carnaval de rua carioca. A esse respeito, vale mencionar que a pesquisa que deu origem a este artigo valeu-se da observação participante em blocos, associações e ligas carnavalescas, além de 
trabalho de campo realizado junto ao Ministério Público do Estado do Rio de Janeiro (MPRJ) - onde, entre 2018 e 2020, uma de nós pôde acompanhar audiências públicas e demais reuniões de um grupo de trabalho destinado aos processos de negociação da festa, com especial atenção às questões relacionadas à segurança e à manutenção da ordem pública. Foram feitas ainda entrevistas com representantes de associações de blocos de rua, de associações de moradores e do MPRJ e pesquisa em material de imprensa, em especial o jornal $O$ Globo, devido à sua densa cobertura anual dos festejos de carnaval. Deste modo, a análise aqui desenvolvida se valeu de dados produzidos a partir de diferentes estratégias metodológicas que permitiram, em seu conjunto, alcançar distintas instâncias e camadas da produção de narrativas e de disputas em torno da organização do carnaval de rua no Rio de Janeiro.

A partir dos dados coletados foi possível pensar o carnaval de rua como resultado de disputas e negociações entre diferentes agentes do Estado e, ao mesmo tempo, como produtor de práticas e territorialidades urbanas. Nesse sentido, tomamos como ponto de partida a proposta de pensar "[...] o Estado por meio de seus agentes, os diferentes interesses que os movimentam, suas práticas e estratégias de luta, os dispositivos de poder que operam em diferentes situações [...]” (TEIXEIRA; LOBO; ABREU, 2019, p. 10). Acreditamos ser possível, com isso, refletir de modo mais amplo sobre os modos como a relação entre norma, espaço e práticas culturais é permanentemente tensionada por diferentes atores.

$\mathrm{O}$ artigo pretende, assim, oferecer uma contribuição ao vasto campo de estudos sobre o carnaval, ${ }^{1}$ discutindo os festejos de rua a partir do entrelaçamento dos campos da antropologia urbana e da antropologia da política. Cabe frisar, ainda, o modo como algumas das questões que emergiram dos atores acompanhados durante a pesquisa apresentaram condições e interpretações continuadas no que tange à política brasileira em sua complexidade, dentre elas a ideia de

1 A partir de diferentes perspectivas, fontes e material empírico, pesquisadores como Queiroz (1992), Soihet (1998), Pereira (2004), Cunha (2001), Gonçalves (2007, 2006), Ferreira (2005), Coutinho (2006) abordaram transformações históricas do carnaval e do país nos séculos XIX e XX, com atenção às disputas envolvendo expressões festivas, dos entrudos às origens das escolas de samba, apresentaram debates transversais aos conflitos entre grupos raciais e sociais diversos. Já as intersecções entre festa e cotidiano têm no trabalho de DaMatta (1997) uma das mais reconhecidas formulações. Cavalcanti (2002) discutiu as materialidades, afetos e estéticas das festas demonstrando o modo como elas transbordam discursos patrimoniais. Já sobre o carnaval de rua a partir da década de 1980, Frydberg $(2016,2017)$ e Frydberg e Eiras (2015) investigaram os atores e configurações da folia dando atenção à tradição, ao direito à cidade e à economia. Ao apresentar preocupações sobre aspectos patrimoniais e raciais, Guimarães (2016) se debruçou sobre os conflitos entre ocupação do espaço público durante a festa e implementação de projetos urbanos. Com enfoque a partir dos anos 2000, Machado (2017) discutiu os modelos neoliberais de gestão da festa. É válido enfatizar que parte do referencial sobre o estado da arte do tema é composto por acadêmicos "nativos", ou seja, participantes do circuito de produção da folia e que se debruçaram sobre ela em seus projetos pessoais, profissionais e acadêmicos, como é o caso de autores como Fernandes (2019) e Couri (2012). 
insuficiência da atuação do Estado. Isso demonstra como o processo de regulação da folia de rua pode ser articulada com essas dinâmicas mais gerais, dialeticamente.

\section{A CRIAÇÃO DO CONTEXTO DE CRISE}

A intervenção federal na segurança pública do estado foi instaurada por Michel Temer em 16 de fevereiro de 2018, por meio do Decreto n ${ }^{\circ} 9.288$ (BRASIL, 2018), dois dias depois da Quarta-Feira de Cinzas - momento que marca, no calendário cristão, o início da quaresma e fim dos dias de excessos. A intervenção, que teve duração de 11 meses, consistiu na retirada do comando das polícias do âmbito do governo do estado, transferindo-o para um general do exército. A medida foi implementada a pedido do então governador Luiz Fernando Pezão, sob o argumento de que, diante da gravidade do quadro de violência enfrentado no Rio de Janeiro, "só com as Forças Armadas e a integração que conseguiremos vencer essa quantidade de armamento de guerra que tem no Rio hoje" (COELHO, 2018).

Cabe frisar que, somadas a essa conjuntura, havia pelo menos duas condições anteriores que dialogavam com os desdobramentos que se dariam a partir de então. A primeira delas foi a situação de calamidade pública nas finanças do estado, instaurada por meio do Decreto $\mathrm{n}^{\mathrm{o}}$ 45.692 de 17 de junho de 2016. De acordo com o texto do decreto, a medida se deu em razão da "grave crise financeira" que teria, dentre outras coisas, "impedido" o estado de "honrar com seus compromissos para a realização dos Jogos Olímpicos e Paralímpicos Rio 2016”, acarretando "severas dificuldades na prestação dos serviços públicos essenciais" (RIO DE JANEIRO, 2016). O decreto (que obteve vigência prorrogada por lei até $2021^{2}$ ) previa, inclusive, a possibilidade de que tal crise financeira culminasse no "total colapso na segurança pública, na saúde, na educação, na mobilidade e na gestão ambiental".

A segunda condição dizia respeito ao regime de recuperação fiscal, uma iniciativa do governo federal para auxiliar os estados "em crise" através da suspensão do pagamento das dívidas à União, tendo como contrapartida a privatização de empresas públicas e o corte de despesas. A entrada do Rio de Janeiro no regime foi formalizada em junho de 2017 e estava vinculada às tentativas de privatização da Companhia Estadual de Águas e Esgotos (CEDAE) e à aprovação de uma lei estabelecendo "teto de gastos" (FREIRE, 2019).

2 Rio de Janeiro, Lei n ${ }^{\circ} 9.163$ de 28 de dezembro de 2020. 
A esse respeito, retomamos Roitman (2014) acerca da necessidade de problematizar os fundamentos do conceito de crise. A autora alerta para a importância da reflexão sobre as bases epistemológicas que sustentam diagnósticos de crise, de modo a compreender como seus usos podem se tornar um elemento central na construção de determinadas narrativas. Isto é, a enunciação da crise acabaria por estabelecer um "momento da verdade" no qual "[...] certas perguntas podem ser feitas enquanto outras são excluídas.” (ROITMAN, 2014, p. 93, tradução nossa). Com o intuito de não reificar essa premissa e assumir as assertivas dos interlocutores como sendo aquelas do pesquisador, mais que compreendê-la como um diagnóstico ou um dado de realidade, é necessário considerar as maneiras pelas quais a crise regula tais narrativas.

O investimento narrativo na ideia de crise promove, assim, um prognóstico de tempo capaz de operar continuamente como produtora de contextos, bem como permite acessar demandas de natureza moral dos atores avaliados. Interessa analisar, portanto, quais práticas podem ser mobilizadas por esse tipo de definição da realidade ou, nos termos da autora, na prática do conceito de crise (ROITMAN, 2014). No caso aqui discutido, isso se expressa em desdobramentos nos modos de lidar com serviços públicos, espaços da cidade e manifestações artístico-culturais que foram alicerçados, por exemplo, nas já mencionadas narrativas de gestores que se valem de diferentes repertórios para corroborar a crise fiscal ou na segurança.

Ao assumir o protagonismo das ações de combate à crise, a intervenção federal, sob o mote da gestão da segurança pública, determinou novos parâmetros de circulação e usos da cidade. Uma vez que agiu como um (re)produtor de desigualdades historicamente constituídas, o comando da intervenção federal teve como foco de atuação áreas de favelas, causando forte impacto no cotidiano de seus moradores. A intervenção emergia, portanto, como um fato decisivo no processo de regulação e ordenamento do uso do espaço, num contexto em que o controle do território pelo Estado passou a ser apresentado pelas autoridades e pelos principais órgãos de imprensa como uma peça-chave na resolução da crise.

Ainda que com sentido diverso daquele acionado no caso do controle territorial em áreas identificadas como violentas, o carnaval de rua sofreu impacto direto deste modelo de gestão da crise em função de sua crescente associação à desordem e à violência. Não por acaso, em meio ao carnaval de 2018, passaram a circular manchetes como essas nos principais jornais do país: “Arrastões, roubos e tiroteios: Rio vive carnaval da violência", "Leblon e Ipanema vivem noite de assaltos e tiroteio após blocos de carnaval" (G1,2018), "Violência e desordem marcam o carnaval do Rio: três PMs são mortos” (NASCIMENTO, 2018; PAMPLONA, 2018), dentre muitas outras com teor similar. O carnaval passava, assim, a integrar o conjunto de narrativas que deram corpo à consolidação da ideia de crise que ganhou rápida aderência na opinião pú- 
blica nos âmbitos local e nacional. Essa noção foi articulada com os números da festa, característica expressa em falas de Pezão que culpava o "gigantismo do carnaval" no ano de 2018: “São 6,5 milhões para tomar conta, 500 blocos e mais um Sambódromo. Não é fácil”. ${ }^{3}$ Portanto, a crise pôde ser apresentada através dos números do carnaval, ao mesmo tempo que eles eram utilizados por representantes de órgãos públicos para realizar o balanço dos festejos, integrar seus processos de regulação e tentativas de ordenamento.

O caso específico do carnaval de rua revela que, embora as ações motivadas pela intervenção federal tenham incidido sobre territórios predeterminados, reforçando dinâmicas historicamente constituídas de segregação socioespacial, elas não se limitaram a isso. Mais do que atuar sobre territórios fixos, sob o comando da intervenção federal as forças de segurança pública passaram a atuar sobre dinâmicas de uso do espaço urbano através do entrelaçamento de discursos de ordem técnica e moral. Não apenas os locais destinados ao desfile de blocos passaram a ser questionados, como também a quantidade de foliões e determinados comportamentos atribuídos ao contexto da folia.

Assim sendo, cabe recordar que a cidade, como materialidade e objeto de análise, deve ser pensada como "[...] uma representação a partir do lugar que os próprios sujeitos ocupam" (AGIER, 1999, p. 16). Isso significa que, mais que um conjunto fixo de espaços previamente identificados, a cidade se constitui de uma constelação de espaços, permanentemente (re)definidos pelo modo como os citadinos - seja como usuários, moradores, transeuntes ou consumidores - praticam seus cotidianos (AGIER, 2011). Nesse sentido, o caso do carnaval de rua nos permite perceber que a intervenção federal incidiu fortemente sobre práticas de circulação e uso do espaço urbano, afetando diretamente o processo de produção da cidade durante o período em que esteve vigente.

É importante dizer que a entrada de novos atores - os militares, há muito tempo presentes no cenário político (LEIRNER, 2020) - na administração pública do estado suscita alguns alertas sobre condições presentes no debate político brasileiro que, em alguma medida, atravessam opiniões historicamente sedimentadas - como as narrativas que reverberam a suposta insuficiência de recursos públicos (FREIRE, 2019). Embora em outros termos, e a partir de outros atores, essa condição também apresentou desdobramentos no caso do carnaval de rua no período de realização da pesquisa.

Esse aspecto será desenvolvido a seguir, a partir de uma reflexão sobre a entrada do MPRJ no debate por intermédio de um de seus braços: o Grupo de Atuação Especializada em

3 Capa $O$ Globo, 14 fev. 2018. 
Segurança Pública (GAESP). Por meio de procedimento administrativo, o MPRJ partia dos “problemas diversos constatados no carnaval de 2018" para propor uma atuação com o objetivo de "acompanhar e fiscalizar o desenvolvimento do planejamento de segurança" da festa. A atuação se daria, assim, a partir de um duplo movimento: primeiro, a identificação de problemas no processo de organização da festa; segundo, o acolhimento de reivindicações de lideranças de ligas e associações de blocos de rua.

Dentre as medidas formuladas pelo MPRJ estava a criação de um protocolo de intenções (MPRJ, 2019) que estipulava a cada um dos órgãos responsáveis suas obrigações no andamento logístico da festa, dentre elas a entrega do planejamento de segurança por parte do governo de estado, além da ampliação no diálogo entre os órgãos responsáveis pela organização do carnaval e sociedade civil. A crise se tornava, enfim, um importante ponto de partida para a construção de uma narrativa sobre os rumos do carnaval de rua.

\section{"EU ORGANIZO 0 MOVIMENTO, EU ORIENTO 0 CARNAVAL"}

Em 2018, o MPRJ deu início a uma série de encontros com representantes de órgãos públicos, com o intuito de tratar da organização do carnaval de rua do ano seguinte. Como desdobramento da iniciativa e conforme previsto no protocolo de intenções, em 2019 o MPRJ criou um Grupo de Trabalho (GT) formado por representantes de associações e ligas de blocos de rua, ${ }^{5}$ de associações de moradores e de órgãos e entidades públicas - como a Empresa de Turismo do Município do Rio de Janeiro (Riotur), a Polícia Militar, a Polícia Civil, os Bombeiros, a Guarda Municipal, a Secretaria de Ordem Pública, a Secretaria Municipal de Fazenda, a Coordenadoria de Controle Urbano, a Coordenadoria de Licenciamento e Fiscalização, o Conselho de Segurança Pública e a Companhia de Engenharia de Tráfego (CET-Rio).

A presença de atores tão diversos na composição do GT anunciou um campo de negociação entre interesses, práticas e valores potencialmente divergentes no que diz respeito à organização do carnaval de rua. Conforme nos alertam Teixeira, Lobo e Abreu (2019, p. 10): “Em cada esfera ou campo social (arte, economia, ciência, religião, política, direito etc.) observamos

4 Conforme consta na Portaria de Instauração de Procedimento Administrativo No 2018.00092841 instaurado pela $3^{\text {a }}$ Promotoria de Justiça de Tutela Coletiva de Defesa da Cidadania da Capital em 16 de fevereiro de 2018.

5 Optamos por não identificar os membros dos blocos e ligas, mas elucidar algumas reivindicações em comum, bem como suas proporções em quantitativo de público e localização geográfica. 
a disputa entre seus atores para estabelecer a hierarquia de práticas, valores, regras e, o mais importante, a própria definição do que seja a realidade e a verdade do mundo". Considerar as lacunas também é de suma importância: a ausência das empresas financiadoras e produtoras do carnaval de rua (respectivamente, a Companhia de Bebidas das Américas - Ambev e a Dream Factory Comunicações e Eventos Ltda.), dos trabalhadores ambulantes e dos representantes dos chamados megablocos foram sentidas especialmente porque esses atores foram enunciados diversas vezes durante os encontros, apesar de não integrarem nenhuma das reuniões.

A proposta inicial do GT era a formação de uma Comissão Permanente de Carnaval de Rua, que se materializaria por meio de encontros realizados entre maio de 2019 , data da primeira audiência pública de balanço do carnaval de rua no MPRJ, e fevereiro de 2020. Uma de nós acompanhou esses encontros na sua totalidade. Durante esse período, foi possível fazer a etnografia das reuniões, observando as muitas camadas de dissensos e negociações que davam forma à interação entre parte dos envolvidos na organização da festa de rua. Assim, a investigação se voltou para esse grupo de atores nesse espaço que se criava e consolidava.

Os encontros ocorreram no prédio do MPRJ, localizado na região central da cidade. Ao chegar ao edifício, que contava em sua área externa com um sistema de vigilância aparentemente complexo, era necessário indicar o destino na bancada de recepção. Foram recorrentes as vezes em que, ao informar que era pesquisadora e gostaria de ser direcionada ao encontro agendado pelo GAESP, os funcionários demonstraram sinais de dúvida e trocaram informações entre si até chegarem à conclusão de que se referia à "reunião do carnaval", nomenclatura que conferia certo caráter de novidade ao tema. Era ainda necessário apresentar algum documento de identificação que seria cadastrado nos computadores da instituição e colar, em lugar visível, a etiqueta adesiva entregue pelos atendentes.

Com o registro finalizado e com a orientação dos funcionários, os convidados eram direcionados a uma sala repleta de cadeiras acolchoadas dispostas em fileiras voltadas de frente a uma mesa e, frequentemente, um equipamento de projeção. Ali se posicionavam os anfitriões do encontro: representantes do MPRJ responsáveis por conduzir e mediar as discussões, incentivar a identificação dos convidados por meio de uma lista de presença e transcrever os debates em atas. Na lateral das fileiras, uma segunda mesa tinha dispostas bandejas com jarras de água e copos de vidro, além de garrafas de café e pequenas xícaras. As reuniões eram compostas por um quórum de cerca de 15 pessoas, dentre elas representantes dos órgãos públicos e entidades civis.

No lugar de brilhos, cores, danças e estandartes, os encontros eram marcados por mesas, assentos, paredes brancas e pelo tradicional aroma de café. Com o desenvolvimento da pesquisa 
foi possível perceber que, embora por vezes tida como espontânea, a folia está situada também num espaço de disputa mais amplo, no qual reuniões, documentos e certo caráter burocrático se fazem presentes.

É importante destacar que participantes do GT reiteradamente destacavam o pioneirismo da iniciativa, que permitia que, pela primeira vez, a realização do carnaval de rua da cidade acontecesse a partir de um diálogo entre atores tão diversos. As reuniões proporcionaram a possibilidade do estabelecimento de debates (e também de atritos) entre membros de órgãos públicos e representantes da sociedade civil, sempre com a intermediação (e também com a interferência) de membros do MPRJ.

Uma percepção que se fez presente logo no início da pesquisa foi a de que os próprios membros do MPRJ que integravam o GT não corroboravam com a leitura de que o carnaval tinha relação direta com a referida crise que culminou na intervenção. Ainda assim, ao considerar - com o respaldo de membros da sociedade civil e de representantes que participavam do GT - um vácuo na organização pública da festa, o MPRJ, que também foi acionado por ligas de blocos de rua, adotou medidas em reação aos fatos transcorridos no carnaval de 2018. Vale destacar, nesse sentido, o depoimento de um representante do MPRJ, segundo o qual a mídia teve participação fundamental no processo de caracterização do carnaval de 2018 como um período de violência exacerbada, culminando na implementação da intervenção federal. Ele ressalta que, apesar de ter havido um recrudescimento dos problemas de segurança,

[...] a gente sabe que isso é uma parcela da questão, que obviamente tem outras questões políticas também envolvidas. Mas de fato houve um momento de influxo de vários fatores que se conjugaram e que mostraram que realmente ali havia um gargalo, a partir dos órgãos públicos, na organização, na tratativa e na logística do carnaval 6 .

Um aspecto fundamental à análise da atuação do GT, bem como das muitas disputas nele travadas, é o fato de que nele havia representantes de blocos localizados principalmente no Centro, Zona Sul e Barra da Tijuca. São blocos de grande, médio ou pequeno porte que se reivindicavam como tradicionais em contraposição àqueles blocos alinhados ao show business, que se organizam em torno da apresentação de artistas conhecidos do grande público. Esses últimos receberam dos integrantes do GT e da imprensa os nomes de blocos show, blocos de artistas ou megablocos, sendo essa última a denominação mais frequente, sendo, inclusive,

6 Entrevista concedida por representante do GAESP/MPRJ em dezembro de 2020. 
adotada pelo site oficial do carnaval do Rio de Janeiro. ${ }^{7}$

A tipificação dos eventos carnavalescos não era um dado trivial e reivindicações de associações de blocos e de moradores, bem como medidas de regramento, perpassaram a discussão dessa categoria. Embora houvesse consenso entre os participantes do GT, a imprensa e os posicionamentos da Riotur em considerar como megablocos os desfiles (com palco ou cortejo de trio elétrico) que reuniam grande quantidade de foliões - valendo-se, portanto, de um critério quantitativo - havia também pontos de dispersão no debate. Lideranças de associações de moradores, por exemplo, procuravam o MPRJ com o argumento de que certos blocos de rua deveriam ser remanejados devido ao aumento expressivo no quantitativo de público, alegando que determinados bairros, como o Leblon, não comportavam mais seus desfiles. Para tanto, defendiam que certas manifestações haviam se tornado megablocos. Os representantes de associações e ligas de blocos, por sua vez, reivindicavam a permanência dos desfiles e uma revisão do conceito de megabloco. Segundo eles, haveria uma diferença entre esses blocos de cunho comercial, que geralmente contam com artistas da cultura de massa ou midiática ${ }^{8}$, e aqueles que se apresentam a partir de uma relação de identidade e territorialidade com determinados espaços da cidade, ainda que ambos apresentassem montante de público equivalente ${ }^{9}$. Esses representantes recorriam, portanto, às narrativas de cunho patrimonial ao enfatizar aspectos territoriais, temporais, de construção coletiva com membros da sociedade, ao mesmo tempo que procuravam se afastar do modelo de eventos promovidos por grandes marcas, por eles relacionados ao risco de descaracterização da festa. ${ }^{10}$

Os representantes de blocos argumentavam também que, diferentemente das agremiações tradicionais, os megablocos seriam focos permanentes de desordem e confusão, considera-

7 Os "megablocos" possuem ao menos uma das seguintes características: ter público de 200 mil participantes ou mais; ter atrações e/ou convidados que se apresentem em formato de shows sobre um palco, caminhão de som ou trio elétrico; ser capitaneado por artistas, cantores, grupos, celebridades ou outros, que se tornem a grande atração”. Disponível em: https://www.carnaval.rio/ Acesso em: 10 jan. 2021.

8 Alguns exemplos de megablocos são: o Bloco Giro do Arar \& Fervo da Lud, que tem como apresentação principal a funkeira Ludmilla, além de outros artistas convidados como Rennan da Penha, Belo e Lexa, com quantitativo de público estimado em 1 milhão de pessoas. O Bloco da Favorita, relativo à festa de mesmo nome da promoter Carol Sampaio, que contou com cerca de 300 mil foliões e o Bloco Carnaval Square, da cantora de axé Claudia Leitte, com público de 120 mil. Dados relativos ao ano de 2020 e disponibilizados pela Riotur (RIO PREFEITURA, 2020b).

9 Casos ilustrativos dessa segunda situação são o Cordão da Bola Preta, Simpatia é Quase Amor, Banda de Ipanema, dentre outros, que no ano de 2020 contaram com quantitativo de público estimado em, respectivamente, 630 mil; 320 mil; 130 mil, segundo dados da Riotur (RIO PREFEITURA, 2020b).

10 Para uma discussão sobre o problema da perda, aproximações e distanciamentos entre mercado e patrimônio cultural e a expansão da noção de patrimônio intangível, ver GONÇALVES $(1996,2007)$. 
ção expressa em uma série de passagens. Um deles chegou a afirmar, em um dos encontros, que "o motivo dessas reuniões foi por conta dos megablocos".11 Tal perspectiva era compartilhada por outros integrantes do GT, como um representante de bairro da Zona Sul da cidade, que comparou a folia nos megablocos a "um campo de batalha". ${ }^{12}$ No mesmo sentido, um representante da polícia militar alertou que, devido ao limite operacional da instituição, haveria a possibilidade de "acontecer uma tragédia" em um megabloco. ${ }^{13}$

Com isso, vemos que, longe de configurar uma disputa de cunho meramente semântico, os conflitos em torno dos critérios de classificação dos blocos mobilizavam aspectos centrais das negociações em torno da ordenação do carnaval de rua. No contexto da crise que deu origem ao GT, os megablocos, fortemente associados a episódios de violência ${ }^{14}$, passavam a figurar como categoria acusatória, numa discussão que acionava aspectos que iam muito além dos problemas de segurança pública.

Com forte ancoragem territorial, os blocos que se reivindicam como tradicionais têm, na sua relação com o espaço, um dos eixos do discurso sobre a sua identidade - e, não menos importante, sobre a sua legitimidade para ocupar as ruas durante o carnaval. Essa característica contrasta com os megablocos, cujo local do desfile costuma variar de ano a ano, a depender do espaço necessário para abrigar a multidão estimada. Esse fato é corroborado na página oficial do carnaval da Riotur com a seguinte afirmação: “desfiles de Mega Blocos exigem logística diferenciada durante suas apresentações, especialmente quanto à segurança do público e mobilidade urbana, demandando mais investimentos em recursos pelos Órgãos Públicos”. Como resultado, a criação e o desfile de megablocos “[...] precisam ser melhor avaliados e devem ocorrer em locais adequados ao atendimento da demanda de segurança, mobilidade, limpeza e controle urbano [...], minimizando assim o impacto desses desfiles na dinâmica urbana da Cidade". ${ }^{15}$

O acionamento do vínculo territorial como elemento de tradição e legitimidade é um elemento central no processo de classificação dos blocos de rua e das negociações que dela

11 Caderno de campo, 29 de novembro de 2019.

12 Caderno de campo, 26 de julho de 2019.

13 Caderno de campo, 11 de setembro de 2019.

14 Episódios representativos desse fato foram confusões de causas desconhecidas seguidas de atuação da polícia militar com o lançamento de bombas de gás lacrimogêneo durante o desfile com trio elétrico do Fervo da Lud \& Giro do Arar, realizado no centro histórico da cidade em 2019. Fato semelhante ocorreu no fim da apresentação de palco do Bloco da Favorita, realizado no bairro de Copacabana e, em sua edição de 2020. Ambos os acontecimentos tiveram feridos e foram amplamente noticiados.

15 Disponível em: www.carnaval.rio. Acesso em: 10 jan. 2021. 
derivam. Conforme defende Haesbaert (1997), a análise do território deve considerar, por um lado, sua dimensão simbólica e cultural - através de uma identidade territorial atribuída por grupos sociais como forma de controle simbólico sobre o espaço onde vivem - e, por outro, uma dimensão concreta, de caráter político-disciplinar, que considera a apropriação e ordenação do espaço como forma de domínio e disciplinarização dos indivíduos. Isso significa que o processo de organização material do carnaval e as dinâmicas de tipificação dos blocos devem ser pensados considerando a regulação do uso do território a partir do entrelaçamento de duas instâncias inextricáveis: as ações da sociedade sobre a base material de sua existência e os sistemas de representação que guiam as intervenções sobre o espaço (RAFFESTIN, 1980). Nesse sentido, podemos pensar na associação entre território e tradição - e na reivindicação de legitimidade que dela deriva - como um processo de produção de territorialidade por parte dos blocos autodenominados tradicionais.

Definida por Sack (1986) como a capacidade de um indivíduo ou grupo para controlar, influenciar ou afetar objetos, pessoas e relações em uma área delimitada, a territorialidade designa o modo como atores sociais se organizam no espaço, dele se apropriam e the conferem significado. É importante lembrar, porém, que as territorialidades não são unívocas. Pelo contrário, são necessariamente múltiplas e sujeitas a sobreposições e mudanças no decorrer do tempo - sendo, portanto, objeto permanente de negociações e conflitos. Isso pôde ser claramente observado nas reuniões do GT, em que, evocando a identidade territorial como um critério de legitimidade para ocupação das ruas, representantes dos blocos autodenominados tradicionais se colocavam em franca oposição aos megablocos, cujo caráter comercial era frequentemente apontado como prova de sua falta de identidade territorial.

A tipificação dos blocos de rua, portanto, não reflete uma unanimidade ou critérios objetivos de classificação, uma vez que é também matéria de conflito. ${ }^{16}$ Nesse sentido, as discussões em torno da definição entre blocos tradicionais e megablocos que tomaram corpo nas reuniões do GT expressam camadas de disputas históricas e culturais em torno da legitimidade de ocupar a rua - e dos modos de ocupá-la - durante o carnaval. Isso revela que a gestão do carnaval de rua passa também, necessariamente, pela gestão de categorias e classificações, por meio das

16 O Projeto de Lei n⿳5556/17, de autoria do vereador Reimont Luiz Otoni do Partido dos Trabalhadores (PT) com o apoio de ligas e associações de blocos na redação, institui o Marco Civil do Histórico Carnaval e tipifica da seguinte forma: "Art. $3^{\circ}$ Serão consideradas como principais manifestações culturais do Carnaval de Rua da cidade do Rio de Janeiro, sem prejuízo do reconhecimento de outras: I- bloco de rua; II- bloco de embalo; III- bloco de frevo; IV- bloco de sujo; V- bloco parado; VI- bloco afro; VII- bloco de enredo; VIII-bloco de rancho; IX- bloco acústico; X- banda carnavalesca; XI- afoxés; XII- jongo; XIII- maracatu; XIV- grupos de Bate-bola ou Clóvis; XV- cordões; XVI- sociedades carnavalescas." 
quais espaços e corpos são regulados, dando diferentes sentidos para a prática de ocupação das ruas.

A seguir, apresentamos algumas modulações entre o carnaval de rua da cidade do Rio de Janeiro e mecanismos de controle burocráticos. Para isso, o enfoque recairá sobre materialidades, produção de narrativas e documentos, principais temas de discussão durante os encontros do GT no MPRJ, e que tangenciam boa parte das disputas entre os diferentes atores engajados na realização da festa.

\section{CONFETES, SERPENTINAS E OUTROS PAPÉIS}

Na região central da cidade, um homem sem camisa, repleto de brilhos de suor, glitter ou purpurina, com orelhas de elfo, fios de cabelo cuidadosamente tingidos de ruivo com spray temporário e empunhando um trombone de vara, carrega, em sua pequena doleira antifurto, uma série de papéis. Entre uma cerveja e outra durante a concentração ${ }^{17}$ do bloco, com público estimado em cerca de vinte mil pessoas, não seria exatamente uma surpresa caso um agente de trânsito, guarda municipal ou policial militar solicitasse algumas vezes a papelada que comprova que o bloco está autorizado a cortejar por aquele logradouro público.

Quando o bloco chegava próximo à metade de seu desfile, um funcionário da CET-Rio se despediu do homem dentro da corda ${ }^{18}$ que envolvia as cerca de cem pessoas, dentre as quais percussionistas, dançarinos e pernas-de-pau: "Estamos indo embora, tivemos algumas observações, mas nada demais, estou levando o relatório". Cada bloco, decerto, tem sua própria expe-

17 A concentração é o momento que antecede o desfile. Nela, tanto o público quanto os integrantes do bloco se reúnem em local previamente agendado para o início do evento. O momento é reservado para algumas atividades operacionais como a afinação dos instrumentos e passagem de som, instalação dos painéis de marcas patrocinadoras (quando é o caso) no trio elétrico ou carro de som, compra de gelo para o isopor ou caixa térmica destinados ao consumo de água e bebidas alcoólicas, ajustes nas fantasias, contato com fotógrafos e imprensa etc., além de marcar uma situação importante de sociabilidade entre os membros do bloco e foliões mutuamente.

18 Embora não encerre o trânsito do público, uma vez que muitos foliões adentram e saem do isolamento - com maior ou menor repressão de integrantes dos blocos de rua -, a corda ajuda a delimitar o espaço da produção, ritmistas e outros envolvidos na dinâmica do bloco e colabora com o andamento do desfile. No caso desse episódio em particular, a corda separava cerca de 100 músicos e artistas de um público de cerca de 20.000 pessoas. Ambas as pontas da corda foram amarradas em um caminhão do tipo trio elétrico posicionado na parte posterior do desfile do bloco e foi carregada por integrantes do grupo, todos não remunerados, responsáveis pela produção, bem como pelos próprios foliões que se voluntariavam e em geral ficavam posicionados na área externa dessa tentativa de isolamento. 
riência ${ }^{19}$ com a possibilidade de, por exemplo, contratação de um produtor especialmente para cuidar dos documentos de autorização. No entanto, na prática, muitas vezes a mesma pessoa que brinca o carnaval é a que maneja os trâmites burocráticos relativos ao bloco.

Os documentos de autorização de um bloco de rua e, com isso, um desfile tido por "autorizado" está condicionado à concessão da Riotur e se relaciona com a dinâmica do Carnaval de Rua Oficial do Rio de Janeiro. Iniciado no ano de 2010, na gestão do prefeito Eduardo Paes, esse modelo propunha ordenar a festa que, até então, não possuía um plano estabelecido para sua realização. A partir de então, o carnaval de rua passou a ser condicionado, por meio do estabelecimento de um Caderno de Encargos e Contrapartidas, aos interesses de grupos privados através de novas propostas de gestão, especificamente a parceria público-privada (PPP) que envolveu, por diversos carnavais, a financiadora Ambev (e suas marcas cervejeiras) e a produtora Dream Factory Comunicações e Eventos Ltda. (empresa responsável por eventos turísticos de grande porte, como o Rock in Rio, a Jornada Mundial da Juventude e a Maratona do Rio). Esse processo, que se relacionou a um "projeto olímpico" de cidade, levava em conta a necessidade de interferência e financiamento da iniciativa privada no carnaval de rua, uma vez que o Estado não poderia "pagar toda a conta" da festa. Nesse sentido, Machado (2017, p. 119, grifo nosso) afirma que "[...] os discursos em torno de uma suposta 'crise financeira' e da 'inexistência de recursos disponíveis ' por parte do Poder Público para a realização da festa são ativados para justificar a realização desse arranjo que supostamente geraria uma economia de milhões aos cofres da cidade [...]" (MACHADO, 2017, p. 119, grifo nosso).

Dentre os papéis necessários ao desfile de um bloco de rua autorizado estão a certidão de anotação de responsabilidade técnica e a ficha de avaliação de risco de eventos especiais (CART/FARE), emitido pelos bombeiros, e o termo de deferimento para realizar evento (ou “nada opor"), emitido pela polícia militar e civil e por hospital de referência da região do desfile. É importante destacar a importância do estatuto burocrático que constitui o carnaval de rua, com a necessidade de conhecimento de engrenagens durante todo o processo de autorização de desfiles de blocos. Nesse sentido, evidenciam-se algumas condições, bem como assimetrias, nos modos de ocupação da rua, em que os grupos com maior força de reivindicação e que sabem manejar esses documentos têm mais facilidade para realizar o desfile. O modo de organização associativa dos blocos demonstra, ele mesmo, como dispositivos de poder podem agir sobre as coletividades assim como o que os corpos devem individualmente levar consigo, e que

19 Conforme enfatizado por Frydberg (2016) numa interlocução com uma representante de ligas e associações de blocos. 
tipos de abordagens devem aguardar durante o desenvolvimento das festividades.

Embora esse modelo de festa tenha sido iniciado na prefeitura de Eduardo Paes, as campanhas contra o uso de dinheiro público no carnaval de rua ganharam força na gestão do prefeito Marcelo Crivella. Os argumentos giraram em torno da oposição entre o carnaval e pautas como a saúde e a educação, colocando em xeque, através de um repertório moral, a legitimidade do investimento público na promoção da folia. Cabe destacar a contraposição entre educação e carnaval, pois ela apareceu reiteradamente em publicidades e na campanha política da prefeitura de Marcelo Crivella. ${ }^{20}$

As polêmicas em torno do financiamento do carnaval revelam intersecções entre a gestão pela escassez de recursos públicos (FREIRE, 2019) e um quadro de valores morais (e certamente religiosos) fazendo do uso do dinheiro público um espaço de disputas morais encampadas pela administração municipal. Por esse princípio, passou a vigorar o argumento de que, diante do quadro de crise e da impossibilidade de transferir o dinheiro da educação para a festa, a operacionalidade do carnaval precisaria ser revista. Mas como isso foi operado? A contraposição discursiva entre maior versus melhor carnaval, medidas de vigilância e a responsabilização da sociedade civil organizadora de blocos foram algumas saídas desenhadas para lidar com esse tipo de enunciado defendido pela prefeitura e discutido no GT do MPRJ.

\section{O MAIOR ESPETÁCULO VERSUS O MELHOR ESPETÁCULO DA TERRA}

Em 2019, Marcelo Alves, então presidente da Riotur ${ }^{21}$, afirmou que "[...] a gente não quer mais ser, e é uma questão de responsabilidade, nós não queremos mais o título de maior carnaval do Brasil, mas de melhor carnaval do Brasil. O maior chega a um ponto de irresponsabilidade". ${ }^{22}$ Seu argumento era de que o efetivo dos órgãos públicos tem um limite que

20 Para as publicidades críticas ao modelo de financiamento do carnaval, ver: https://bit.ly/3yqg6IR. Acesso em: 28 jun. 2021. Para uma crítica e réplica a esse enunciado, ver os seguintes pronunciamentos do vereador Tarcísio Motta do Partido Socialismo e Liberdade (PSOL) disponível em: https://bit.ly/3u3V3s4 e https://bityli.com/ phE1R. Acesso em: 20 jan. 2020.

21 Alves foi afastado em março de 2020 devido aos escândalos de corrupção na própria instituição envolvendo o seu irmão Rafael Alves e a prefeitura de Marcelo Crivella.

22 Informações concedidas por Marcelo Alves durante Audiência Pública realizada no MPRJ em 23 de maio de 2019. As passagens a seguir se referem ao mesmo evento. 
precisaria ser considerado na organização do carnaval de rua para que não ocorressem cenários de violência. Além de resgatar o que chamou de caos em anos anteriores, provavelmente em referência ao carnaval de 2018, a declaração fez ainda menção aos habituais pronunciamentos de seu antecessor na presidência da Riotur, Antonio Pedro Figueira de Mello, que dizia estar provado, “[...] de uma vez por todas, que o maior carnaval do Brasil é aqui, no Rio de Janeiro, e [que] a gente faz a maior operação urbana do mundo" (SERODIO, 2012).

A posição de Marcelo Alves foi corroborada por dados apresentados acerca da diminuição no número de desfiles de blocos de rua. De acordo com ele, entre 2018 e 2019 houve uma diminuição de $15 \%$ no número de desfiles, diminuindo de 608 para 498, em contraposição aos cerca de 700 desfiles inscritos para pedidos de autorização. É importante ressaltar que os números se referem especificamente ao carnaval de rua oficial e aos desfiles de blocos autorizados, o que não necessariamente indica que blocos não contabilizados, ou desautorizados, deixaram de sair às ruas nos dias de folia.

Marcelo Alves informou que tal redução foi feita em respeito aos moradores, "que foram extremamente ouvidos". Com efeito, a demanda pela diminuição no tamanho e no número de blocos de rua foi marcante entre as associações de moradores da Zona Sul da cidade. Dentre as principais queixas apresentadas por representantes dessa categoria estavam o consumo de drogas ilícitas e bebidas alcoólicas, problemas no esquema de organização dos trabalhadores ambulantes, "vandalismos" e urina nas ruas. As reclamações culminavam, via de regra, no pedido de remanejamento de blocos para outras regiões da cidade, fato que corroborou com a idealização do que convencionou-se chamar de blocódromo, elemento que ganhou espaço nos debates sobre o carnaval em 2018, quando prefeitura apresentou a proposta de um circuito fechado de apresentações carnavalescas chamado Arena Carnaval, no Parque dos Atletas, na Zona Oeste da cidade. O projeto, que não chegou a ser implementado, foi amplamente criticado por representantes de ligas e associações de blocos, que viam na medida uma afronta à relação indissociável entre os desfiles carnavalescos e o espaço urbano.

A oposição maior versus melhor foi o mote da gestão da prefeitura de Marcelo Crivella, tornando-se um bordão reiteradamente repetido por agentes da municipalidade (RIO PREFEITURA, 2019). Ela passou a reverberar (e, dialeticamente, a alimentar) as questões mais discutidas durante as reuniões do GT do MPRJ: a quantidade de blocos cadastrados na Riotur; a quantidade de desfiles autorizados e quantidade de foliões, sempre pensados em relação à quantidade de banheiros químicos disponíveis, à capacidade dos meios de transporte público (sobretudo o metrô) e aos limites operacionais das polícias e dos órgãos de saúde pública.

Em resposta a isso, algumas medidas foram tomadas pela prefeitura, ganhando espaço 
nas reuniões do MPRJ, nas quais receberam algum tipo de respaldo e tentativas de intermediação do conflito entre agentes da prefeitura, associações de moradores e representantes de blocos. Uma delas se deu em 2019, dois meses antes do início do carnaval, quando a Riotur lançou uma portaria que exigia dos blocos com estimativa de público de mais de cinco mil foliões a necessidade de instalação de postos médicos, contratação ambulâncias UTIs móveis, médicos e enfermeiros para cobrir o período de seus desfiles $(\mathrm{G} 1,2019)$. A contratação era pré-requisito para a autorização dos bombeiros, uma das condições para a saída dos blocos, e, portanto, fundamental à aquisição da autorização para o desfile junto à Riotur. Durante as reuniões, diversos representantes de ligas de blocos se mostraram contrários à exigência, alegando a discrepância entre a realidade financeira dos blocos e os valores cobrados pelos serviços exigidos. ${ }^{23}$ Os representantes alegavam, ainda, que o fornecimento de serviços de atendimento à saúde seria atribuição do poder público. A partir da intermediação do MPRJ, a decisão foi revista e se manteve a operação de anos anteriores: as estruturas de saúde montadas pela empresa produtora e operada pela Secretaria Municipal de Saúde.

Outra medida da prefeitura que causou desconforto entre os representantes de blocos foi a determinação de aplicação de multas aos blocos que saíssem sem autorização da Riotur em 2020. ${ }^{24}$ A medida contaria com o auxílio de redes de monitoramento como as mochilink, ou "mochilas espiãs", modo como foi apelidado o equipamento ${ }^{25}$ com duas câmeras integradas e visão $360^{\circ}$ com capacidade de realizar envio de imagens ao Centro de Operações da Prefeitura (COR). O projeto de controle tecnológico, com o uso de recursos informáticos, faz parte de um processo mais amplo de produção da ordem urbana (CARDOSO; HIRATA, 2017) a partir da vigilância dos corpos como dispositivo de poder.

A ideia de um carnaval melhor, apresentado pelo presidente da Riotur, convergia não só com a diminuição no número de desfiles de blocos carnavalescos cadastrados pela instituição, ou seja, autorizados a cortejar pelas ruas da cidade, como também com as medidas de regulação e ordenamento que vinham sendo viabilizadas pela prefeitura por meio de tecnologias de vigilância e dos documentos de autorização. Assim, além do aspecto quantitativo e da capacidade

$23 \mathrm{Na}$ época, blocos que desfilavam com equipamento de som e público estimado em quinze mil foliões tiveram em torno de $\mathrm{R} \$ 10.000,00$ como total dos gastos com as medidas de saúde.

24 As multas, com valor inicial de $\mathrm{R} \$ 1.300,00$, levariam em conta a quantidade de lixo coletado pela Comlurb (Companhia de Limpeza Urbana) a partir da Lei municipal 3.273/01, que normatiza o sistema de limpeza urbana e teve no Programa Lixo Zero uma das mais importantes tentativas de aplicabilidade através da abordagem e aplicação de multas a pessoas que descartassem lixo irregularmente.

25 Operado por agentes da Secretaria Municipal de Envelhecimento Saudável, Qualidade de Vida e Eventos. (MOURA, 2020. RIO PREFEITURA, 2020a) 
de operação dos órgãos públicos, a definição de um carnaval de rua melhor estaria vinculada também a uma série de regulações e ordenamentos que delimitam o que vem a ser o carnaval tido por oficial.

As situações descritas revelam que o GT se constituiu como um espaço de negociação, no qual o MPRJ atuava como mediador entre as determinações da prefeitura e os diferentes atores envolvidos na organização do carnaval. Em meio aos desconfortos e conflitos gerados pelas medidas que visavam a normatização da festa, cabia ao MPRJ mediar não apenas as questões de ordem prática, mas também aquelas relacionadas à gestão de classificações e às moralidades.

Por meio do GT, o MPRJ punha em diálogo o universo das normas, apresentadas sob a forma de decretos e resoluções, e o mundo das práticas, que se materializavam nas demandas dos órgãos e entidades ali representados. A esse respeito, cabe lembrar, acompanhando Velho (2001), que os mediadores atuam no estabelecimento de relações entre grupos e categorias sociais distintos, constituindo-se como importantes agentes de transformação. Segundo o autor, ao transitar por diferentes fontes de informações e repertórios de valores, os mediadores têm o potencial de alterar fronteiras do mundo social, colocando em contato diferentes visões e definições da realidade (SCHÜTZ, 1983). Nesse sentido, ao atuar na organização do carnaval de rua, o MPRJ acabava também se colocando como agente na produção de classificações e territorialidades e, portanto, da própria cidade.

\section{CONSIDERAÇÕES FINAIS}

As situações analisadas no decorrer deste artigo se desdobram em modos de (des)autorizações na ocupação do espaço público a partir da nomeação da crise: a crise fiscal, a crise na segurança pública e a crise na saúde pública, acionadas por diferentes atores na promoção de modos de controle e criação de novas responsabilidades na realização do carnaval de rua. A governança pela norma e controle burocrático são mesclados a outras condições materiais e infraestruturais, com a presença de dispositivos de vigilância e uma ampla rede de monitoramento, tentativas de intimidação de blocos de rua e de seus organizadores. Isso aparece, por exemplo, no caso das tentativas de aplicação de multas e da responsabilização dos blocos pela saúde dos foliões, com a necessidade de contratação de ambulâncias e UTIs móveis.

Cabe frisar como a tentativa de produção de uma ordem pública no âmbito do carnaval foi sendo associada a sistemas burocráticos explicitados pelo processo de pedido de autorização 
para desfiles de blocos. Isso demonstra como é necessário que representantes de blocos saibam manejar determinados códigos para ocupar a rua de modo "legítimo" e juridicamente "seguro". Assim, segurança e ordem públicas são condições reiteradamente presentes no contexto do estado do Rio de Janeiro e fundamentais também nas discussões sobre a folia. Sua dimensão gigantesca fez ainda com que se alterasse o mote da instituição organizadora da festa, a Riotur, da busca pelo melhor em detrimento do maior carnaval do mundo. Esse fato levou em conta o modo de alocação de recursos tidos por escassos, e fez emergir um quadro de valores morais que punham a folia como antagonista de outros serviços públicos essenciais, como a saúde e a educação.

Nesse espaço conflitivo foram se configurando as narrativas de necessidade de gestão compartilhada da folia, seja com iniciativas privadas, através da militarização da segurança pública ou da intermediação do MPRJ. Chama a atenção, assim, a aparente excepcionalidade de um evento anual como o carnaval de rua no Rio de Janeiro, que fez com que, sem marcos regulatórios ou gestão em continuidade, o MPRJ se apresentasse como um ator apto a desempenhar esforços de mediação dos efeitos da crise sobre o carnaval, diante de um quadro de insuficiência ou inoperância do Estado.

Deste modo, vimos como as negociações sobre o carnaval de rua partiram de um cruzamento entre norma, espaço e cultura, no qual a burocracia e os documentos de autorização de desfiles de blocos foram justapostos às condições espaciais e de serviços públicos da própria cidade. Tais negociações se deram, sobretudo, no espaço do GT especialmente criado para esse fim, no qual foram postos em contato alguns dos principais agentes responsáveis pela realização da festa. De modo pioneiro, esses encontros permitiram o diálogo entre visões de mundo divergentes sobre os sentidos do carnaval, explicitando a complexidade dos arranjos e classificações que dão forma a uma festa que tem como tônica dominante a espontaneidade. Por fim, é importante destacar que o estudo de caso da organização do carnaval de rua em meio ao contexto tido como de crise permitiu entrever dinâmicas nem sempre explícitas do processo de construção da cidade, permanentemente marcado pelas relações entre práticas, representações e normas, bem como pela atuação de órgãos e atores em diferentes escalas.

\section{REFERÊNCIAS}

1. AGIER, M. L'invention de la ville: Banlieues, townships, invasions et favelas. Paris: Éditions des Archives Contemporaines, 1999. 
2. AGIER, M. Antropologia da cidade: lugares, situações, movimentos. São Paulo: Terceiro Nome, 2011.

3. BANDNEWS TV. Presidente Michel Temer concede entrevista. BandNews TV, São Paulo, 16 fev. 2018. Disponível em: https://www.facebook.com/502267346597124/ videos/1027250174098836/. Acesso em 13 jun. 2021.

4. BRASIL. Decreto $\mathbf{n}^{\mathbf{0}} \mathbf{9 . 2 8 8}$ de 16 de fevereiro de 2018. Decreta intervenção federal no Estado do Rio de Janeiro com o objetivo de pôr termo ao grave comprometimento da ordem pública. Disponível em: https:/www2.camara.leg.br/legin/fed/decret/2018/ decreto-9288-16-fevereiro-2018-786175-publicacaooriginal-154875-pe.html. Acesso em: 24 jun. 2021.

5. CARDOSO, B.; HIRATA, D. Dispositivos de inscrição e redes de ordenamento público: uma aproximação entre a teoria do ator-rede (ANT) e Foucault. Revista Sociologia e Antropologia, v. 7, n. 1, p. 77-103, 2017. Disponível em: https://www.scielo.br/j/sant/a/ HDvS3bFYRWR3Fm5Y4mmF5Ld/abstract/?lang=pt. Acesso em: 24 abr. 2021.

6. CAVAlCANTI, M. L. V. C. Os sentidos no espetáculo. Revista de Antropologia, v. 45, n. 1, p. 37-78, 2002. Disponível em: https://dx.doi.org/10.1590/s003477012002000100002. Acesso em: 24 abr. 2021.

7. COELHO, H. Pezão diz que só com intervenção federal é possível 'vencer armas de guerra' no RJ. G1, Rio de Janeiro, 16 fev. 2018. Disponível em: https://g1.globo.com/ rj/rio-de-janeiro/noticia/pezao-diz-que-so-com-intervencao-federal-e-possivel-vencerarmas-de-guerra-que-o-rj-tem-hoje.ghtml. Acesso em: 13 jan. 2021.

8. CORRÊA, D. Carnaval do Rio deve reunir 7 milhões de foliões. Agência Brasil, Rio de Janeiro, 15 fev. 2019. Disponível em: https://agenciabrasil.ebc.com.br/geral/ noticia/2019-02/carnaval-do-rio-deve-reunir-7-milhoes-de-folioes. Acesso em: 13 jan. 2021 .

9. COURI, C. The Growth of Percussion Workshop in Carnival in Rio: From Countermovement to Commodification of Culture? 2012. 44 f. Dissertação (Mestrado em Cultural and Creative Industries) - Kings College London, Londres, 2012.

10. COUTINHO, E. G. Os cronistas de Momo: imprensa e Carnaval na Primeira República. Rio de Janeiro: Editora UFRJ, 2006.

11. CUNHA, M. C. Pereira. Ecos da folia: uma história social do Carnaval carioca entre 1880 e 1920. São Paulo: Companhia das Letras, 2001.

12. DAMATTA, R. Carnavais, malandros e heróis: para uma sociologia do dilema brasileiro. Rio de Janeiro: Rocco, 1997.

13. DEWEY, J. Logic: The Theory of Inquiry. New York: Henry Hold and Company, 1938.

14. FERNANDES, R. Meu bloco na rua: a retomada do carnaval de rua do Rio de Janeiro. 
Rio de Janeiro: Civilização Brasileira, 2019.

15. FERREIRA, F. Inventando carnavais: o surgimento do carnaval carioca no século XX e outras questões carnavalescas. Rio de Janeiro: Editora UFRJ, 2005.

16. FOLHA DE SÃO PAULO. Em meio à violência, RJ ainda não tem plano de segurança para o Carnaval. Folha de São Paulo, São Paulo, 30 jan. 2018. Disponível em: https:// www1.folha.uol.com.br/cotidiano/2018/01/1954464-em-meio-a-violencia-rj-aindanao-tem-plano-de-seguranca-para-o-carnaval.shtml. Acesso em: 13 jan. 2021.

17. FREIRE, L. A gestão da escassez: uma etnografia da administração de litígios de saúde em tempos de "crise". 2019. 388 f. Tese (Doutorado em Antropologia Social) - Programa de Pós-Graduação em Antropologia Social do Museu Nacional, Universidade Federal Rio de Janeiro, 2019. Disponível em: http://objdig.ufrj.br/72/teses/902376.pdf. Acesso em 28 jun. 2021.

18. FRYDBERG, M. B. “A maioria dos blocos lá trabalham bloco como produto sim": Uma análise do carnaval de rua do Rio de Janeiro através das suas práticas empreendedora e seus múltiplos significados. Pol. Cult. Rev., v. 9, n. 2, p. 605-625, dez. 2016. Disponível em: https://periodicos.ufba.br/index.php/pculturais/article/view/17798. Acesso em: 28 jun. 2021.

19. FRYDBERG, MB. Os processos de (re)tradicionalização e patrimonialização no carnaval dos blocos de rua no Rio de Janeiro. pragMATIZES: Revista Latino Americana de Estudos em Cultura, Ano 8, n. 14, out. 2017. Disponível em: https://periodicos.uff.br/ pragmatizes/article/view/10474. Acesso em: 28 jun. 2021.

20. FRYDBERG, M. B.; EIRAS, R. E. C. Abre-alas, que eu quero passar: Contribuições para pensar a economia da festa através dos blocos de rua na cidade do Rio de Janeiro. In: CASTRO, F. L.; TELLES, M. F. P. Dimensões econômicas da cultura: experiência no campo da economia criativa no Rio de Janeiro. Rio de Janeiro: Lumen Juris, p. 195224, 2015.

21. G1. Leblon e Ipanema vivem noite de assaltos e tiroteio após blocos de carnaval. G1, Rio de Janeiro, 12 fev. 2018. Disponível em: https://g1.globo.com/rj/rio-de-janeiro/ carnaval/2018/noticia/serie-de-assaltos-e-tiroteio-apavoram-moradores-na-zona-suldo-rio-durante-o-carnaval.ghtml. Acesso em: 13 jan. 2021.

22. G1. Riotur cria regras que obrigam blocos com mais de 5 mil pessoas a contar com estrutura de saúde. G1, Rio de Janeiro, 04 jan. 2019. Disponível em: https://g1.globo. $\mathrm{com} / \mathrm{rj} /$ rio-de-janeiro/carnaval/2019/noticia/2019/01/04/riotur-cria-regras-queobrigam-blocos-com-mais-de-5-mil-pessoas-a-contar-com-estrutura-de-saude.ghtml. Acesso em: 13 jan. 2021.

23. GONÇALVES, R. S. Os ranchos carnavalescos e o prestígio das ruas: territorialidades e sociabilidades no carnaval carioca da primeira metade do século XX. Textos escolhidos de cultura e arte populares, v. 3, n. 1, p. 71-80, 2006. 
24. GONÇALVES, R. S. Os Ranchos pedem passagem. Rio de Janeiro: Secretaria Municipal das Culturas, 2007.

25. GONÇALVES, J. R. A retórica da perda: os discursos do patrimônio cultural no Brasil. Rio de Janeiro: UFRJ/IPHAN, 1996.

26. GONÇALVES, J. R. Os limites do patrimônio. In: LIMA FILHO, M. F.; ECKERT, C.; BELTRÃO, J. F. (org.). Antropologia e patrimônio cultural: diálogos e desafios contemporâneos. Blumenau: ABA; Nova Letra. p. 239-248, 2007.

27. GUIMARÃES, R. S. Patrimônios e conflitos de um afoxé na reurbanização da região portuária carioca. Mana, v. 22, n. 2, p. 311-340, 2016. https://www.scielo.br/j/mana/ a/3B9gK5XwYqg5d55GHNvLyyd/abstract/?lang=pt. Acesso em 28/06/2021.

28. HAESBAERT, R. Des-territorialização e identidade: a rede "gaúcha" no Nordeste. Rio de Janeiro: EdUFF, 1997.

29. MACHADO, F. A. S. Ei você aí, me dá um dinheiro aí?: conflitos, disputas e resistências na cidade do Rio de Janeiro. Rio de Janeiro: Lumen Juris, 2017.

30. MOURA, C. Blocos de carnaval não oficiais serão multados pela Prefeitura do Rio: querem 'baderna', diz secretário. O GLOBO, Rio de Janeiro, 12 fev. 2020. Disponível em:https://oglobo.globo.com/rio/carnaval/blocos-de-carnaval-nao-oficiais-seraomultados-pela-prefeitura-do-rio-querem-baderna-diz-secretario-24244464. Acesso em: 09 dez. 2020.

31. MINISTÉRIO PÚBLICO DO ESTADO DO RIO DE JANEIRO. MPRJ divulga Protocolo de Intenções para o Carnaval de Rua 2019 na cidade do Rio. MPRJ, Rio de Janeiro, 21 fev. 2019. Disponível em: https://www.mprj.mp.br/home/-/detalhe-noticia/ visualizar/69835. Acesso em: 18 jan. 2021.

32. NASCIMENTO, R. Arrastões, roubos e tiroteios: Rio vive carnaval de violência. $\mathbf{O}$ GLOBO, Rio de Janeiro, 12 fev. 2018. Disponível em: https://oglobo.globo.com/rio/ carnaval/2018/arrastoes-roubos-tiroteios-rio-vive-carnaval-de-violencia-22391879 Acesso em: 13 jan. 2021.

33. NUNES, M. Carnaval no Rio é marcado por um arrastão de violência. O GLOBO, Rio de Janeiro, 13 fev. 2018. Disponível em: https://oglobo.globo.com/rio/carnaval-no-riomarcado-por-um-arrastao-de-violencia-22392812 . Acesso em: 09 dez. 2020.

34. PEREIRA, L. A. M. O carnaval das letras: literatura e folia no Rio de Janeiro do século XIX. 2. ed. Campinas: Editora da UNICAMP, 2004.

35. QUEIROZ, M. I. P. Carnaval brasileiro: o vivido e o mito. São Paulo: Brasiliense, 1992.

36. LEIRNER, P. O Brasil no espectro de uma guerra híbrida: militares, operações psicológicas e política em uma perspectiva etnográfica. 1. ed. São Paulo: Alameda, 2020. 
37. PAMPLONA, N. Violência e desordem marcam o carnaval do Rio: três PMs são mortos. Folha de S. Paulo, Rio de Janeiro, 14 fev. 2018. Disponível em: https://www1.folha. uol.com.br/cotidiano/2018/02/violencia-e-desordem-marcam-carnaval-do-rio-tres-pmsao-mortos.shtml. Acesso em: 13 jan. 2021.

38. RAFFESTIN, C. Pour une Géographie du pouvoir. Paris, Libraires techniques, 1980.

39. RIO DE JANEIRO. Decreto $\mathbf{n}^{\mathbf{0}} \mathbf{4 5 . 6 9 2}$ de 17 de junho de 2016. Decreta estado de calamidade pública, no âmbito da administração financeira do Estado do Rio de Janeiro e dá outras providências. Disponível em: http://www.fazenda.rj.gov.br/sefaz/ content/conn/UCMServer/path/Contribution \%20Folders/site_fazenda/legislacao/ tributaria/decretos/2016/DECRETO\%20N.\%C2\%BA\%2045692\%20DE\%2017\%20 DE\%20JUNHO\%20DE\%202016.htm\#: :text=DECRETO\%20N.\%C2\%BA\%20 $45.692 \% 20$ DE, JANEIR O \% 2C \% 20 E $\% 20$ D \% C 3\% $81 \% 20$ OUTRAS $\% 20$ PROVID\%C3\%8ANCIAS. Acesso em: 24 jun. 2021.

40. RIO DE JANEIRO. Lei $\mathbf{n}^{\circ} 3.273$ de 06 de setembro de 2001. Dispõe sobre a Gestão do Sistema de Limpeza Urbana no Município do Rio de Janeiro. Disponível em:https:// leismunicipais.com.br/a1/rj/r/rio-de-janeiro/lei-ordinaria/2001/328/3273/lei-ordinarian-3273-2001-dispoe-sobre-a-gestao-do-sistema-de-limpeza-urbana-no-municipio-dorio-de-janeiro?q=3273\%20. Acesso em: 24 jun. 2021.

41. RIO DE JANEIRO. Lei 9.163 de 28 de dezembro de 2020. Altera a lei $\mathrm{N}^{\mathbf{0}} \mathbf{7 . 4 8 3}$, de 08 novembro de 2016, alterada pela lei $\mathrm{N}^{0} \mathbf{7 . 6 2 7}$, de 09 de junho de 2017, pela lei $\mathrm{N}^{\mathrm{o}} \mathbf{8 . 2 7 2}$, de 27 de dezembro de 2018, e pela lei $\mathrm{N}^{\mathrm{o}} \mathbf{8 . 6 4 7}$, de 09 de dezembro de 2019, que reconhece o estado de calamidade pública no âmbito da administração financeira declarado pelo decreto $\mathrm{N}^{\mathrm{0}}$ 45.692, de 17 de junho de 2016. Disponível em: http://alerjln1. alerj.rj.gov.br/wwwalerj.nsf/pages/principal. Acesso em: 24 jun. 2021.

42. RIO DE JANEIRO. Projeto de Lei 556/2017. Institui o Marco Civil do Histórico carnaval de rua da cidade do Rio de Janeiro. Disponível em http://aplicnt.camara. rj.gov.br/APL/Legislativos/scpro1720.nsf/0cfaa89fb497093603257735005eb2bc/ e8dcdc21cbdb41c5832581ca004bed74?OpenDocument. Acesso em: 24 jun. 2021.

43. RIO PREFEITURA. Carnaval 2019 terá megaoperação da Prefeitura do Rio. Rio Prefeitura, Rio de Janeiro, 27 fev. 2019. Disponível em: http:/www.rio.rj.gov.br/web/ guest/exibeconteudo?id=9279042 . Acesso em: 09 dez. 2020.

44. RIO PREFEITURA. Carnaval 2020: Prefeitura anuncia megaoperação. Rio Prefeitura, Rio de Janeiro, 07 fev. 2020a. Disponível em: https://prefeitura.rio/rio-faz-destaque/ carnaval-2020-prefeitura-anuncia-megaoperacao/. Acesso em: 27 dez. 2020.

45. RIO PREFEITURA. Melhor carnaval de todos os tempos no Rio: mais de 10 milhões de foliões e alto índice de aprovação por turistas. Rio Prefeitura, Rio de Janeiro, 02 mar. 2020b. Disponível em: https://prefeitura.rio/rio-acontece/melhor-carnaval-detodos-os-tempos-no-rio-mais-de-10-milhoes-de-folioes-e-alto-indice-de-aprovacaopor-turistas/\#: :text $=\mathrm{O} \% 20$ Carnaval $\% 20 \mathrm{Rio} \% 202020 \% 20$ foi,bilh $\% \mathrm{C} 3 \% \mathrm{~B} 5$ es $\% 20$ 
em\%20movimenta\%C3\%A7\%C3\%A3o\%20econ\%C3\%B4mica\%20e. Acesso em: 26 fev. 2021

46. ROITMAN, J. Anti-crisis. Durham/London: Duke University Press, 2014.

47. SACK, R. D. Human Territoriality: its Theory and History. London: Cambridge University Press, 1986.

48. SCHÜTZ, A. Dom Quixote e o problema da realidade. In: LIMA, L. C. Teoria da literatura em suas fontes. Rio de Janeiro: F. Alves, p. 191-213, 1983.

49. SERODIO, G. Carnaval gera US\$ 850 milhões para o Rio de Janeiro. Valor Econômico, Rio de Janeiro, 27 fev. 2012. Disponível em: https://valor.globo.com/brasil/ noticia/2012/02/27/carnaval-gera-us-850-milhoes-para-o-rio-de-janeiro.ghtml . Acesso em: 14 jan. 2021.

50. SOIHET, R. A subversão pelo riso: estudos sobre o carnaval carioca da Belle Époque ao tempo de Vargas. Rio de Janeiro: Fundação Getúlio Vargas, 1998.

51. TEIXEIRA, C. C.; LOBO, A.; ABREU, L. E. Nada precisa ser como é: etnografias das instituições, práticas de poder e dinâmicas estatais. In: TEIXEIRA, C. C.; LOBO, A.; ABREU, L. E. (org.). Etnografias das instituições, práticas de poder e dinâmicas estatais. Brasília: ABA Publicações, 2019.

52. VELHO, G. Biografia, trajetória e mediação. In: VELHO, G.; KUSCHNIR, K. (ed.). Mediação, cultura e política. Rio de Janeiro: Aeroplano, 2001.p. 13-28.

Ana Paula Rocha de Oliveira

Doutoranda e Mestre pelo Programa de Pós-Graduação em Sociologia e Antropologia da Universidade Federal do Rio de Janeiro. Bacharel em Museologia pela Universidade Federal do Estado do Rio de Janeiro. Integrante do Urbano - Laboratório de Estudos da Cidade do Instituto de Filosofia e Ciências Sociais da Universidade Federal do Rio de Janeiro. ID ORCID: https://orcid.org/0000-0002-6084-6142. E-mail: anapaula.rocha.oli@gmail.com. Colaboração: Pesquisa bibliográfica, Pesquisa empírica, Análise de dados, Redação.

\section{Julia Galli O’Donnell}

Professora do Departamento de Antropologia Cultural e do Programa de Pós-Graduação em Sociologia e Antropologia da Universidade Federal do Rio de Janeiro. Doutora pelo Programa de Pós-graduação em Antropologia Social do Museu Nacional/UFRJ. Coordenadora do Urbano - Laboratório de Estudos da Cidade do Instituto de Filosofia e Ciências Sociais da Universidade Federal do Rio de Janeiro. ID ORCID: https://orcid.org/0000-0003-2174-8440. E-mail: juliagodonnell@gmail.com. Colaboração: Pesquisa bibliográfica, Análise de dados, Redação, Revisão. 